\title{
EFFECT OF POST TRAUMA STRESS DISORDER ON SOCIAL SETTINGS OF WOMEN: A STUDY IN DISTRICT SARGODHA, PUNJAB PAKISTAN
}

\author{
Urwah Sheikh \\ M.Phil. Department of Sociology \& Criminology, \\ University of Sargodha \\ urwahsheikh015@gmail.com
}

\author{
Humera Amin \\ Assistant Professor, Department of Sociology \& Criminology, \\ University of Sargodha, \\ humeraamin@yahoo.com \\ Farhana Nosheen \\ Assistant Professor, Department of Home Economics, \\ Government College University, Faisalabad \\ farhananosheen@gcuf.edu.pk
}

\begin{abstract}
General distress is a condition experienced by different women in traumatic situations. PostTraumatic stress disorder is measured as a multi-dimensional concept, which would contain a diversity of reasons The main objective of this study was to explore the social and psychological factors of pre traumatic and post trauma effects on women patients. The study was quantitative in nature and used well-structured questionnaire to collect the data from women patients who are suffering from PTSD with sample size N=304. Women who suffered from traumatic situation may have short-term difficulty in adjusting, coping and focusing on their task activities. Multi stage random sampling technique was used to collect the data from four psychiatric hospitals (public \& private) out of 9 in district Sargodha Punjab, Pakistan. SPSS was used to analyze the research data. It is reported that the most prevalent age group of women was $18-28$ (51.5\%) in this study. Majority of them have low family income up to 11,000-24,000 per month. Most of the women patients have an experience of different types of stress including upset memory, bad dreams, negative emotions and poor adjustment in relationship within family and society. Social and emotional support mechanism should be helpful to the women in handling traumatic situations. Government should increase funding for research on Post Trauma Stress Disorder (PTSD) on Women case studies.
\end{abstract}

Key words: Traumatic effects, Stress, Women, Health, Social settings, Treatment.

\section{INTRODUCTION}

Women all around the globe are being enfolded in traumatic stress without being aware of it; therefore, it is very essential to study about it. Trauma is not restricted to any individual, it happens even in social circles. Thus, it is vital to understand the role of interactive and social aspects. Social setups assist in various traumatic effects.

The study on traumatic situations and the work done on it opens up that experiencing trauma situation is a sensitive matter specially for the women. Different methods, such as individual modification are applied to find out concerns about various traumatic conditions. Such social connections help pounder over situations and the way treatment is performed (Frans et al., 2005). The domain to psycho traumatology usually shows the issues of various individuals and give a good understanding about the traumatic effect, helping women to overcome traumatic experiences. It is easy for women to cover up the traumatic situations due to the improvements being made. Very few empirical improvements have been concluded for the patients of trauma which shows the lack of empirical research carried out on them. Few works have been done, which shows that there is a need to articulate better perspective (Norris \& Olff, 2009). Based on number of studies, it is presumed that 
increased level of trauma could be harnessed through the development of social support mechanisms. On the other hand, those who don't create social attachments are likely to involve in negative behavior of distress and trauma.

In order to deal with the trauma, slight efforts have been made to formulate multiple strategies. A clear perspective of it is essential to scrutinize its impact on trauma and the range to which it effects the stressed women. Social support is helpful for people if they are facing any traumatic situation as indicated in the study, it forbids the upshot of trauma along with the use of several strategies involved in the treatment (Gill et al., 2008).

In everyday life, there are multiple reasons of stress. Men and women have different perspective of stress, such as poverty, health issues, job insecurity, relationship problems and correlation issues (Gill et al., 2008). In women, it is probably the roles and responsibilities they perform in a family, community and society. Universally, role of women encompasses family obligations, household chores, caregiving for offspring and occupational tasks. As the responsibilities and expectations intensify, the women get stressed (Coitre et al., 2019). They may sense themselves to fall short of expectations for them and others. Often women put the family's demands first rather than fulfilling their own essentials. While working at high stress levels, women are incapable to identify what their needs are in actual.

Based on contemporary studies of gender roles, those men who sharply adhere to the conventional norms of being masculine come off to be more aggressive towards their counterparts. Furthermore, they practice violence against women. Nevertheless, acute violence has generally been studied in response to masculine gender role. Along with it, there are other studies confirming the situations where aggression of man effects the roles of women and resultantly, destructions of their gender role indirectly has an impact on man's aggression.

Violence on women is the concurrent social issue around the globe. Since many decades, violence against women has been a significant researchable issue in family, history and socio cultural studies. Directly or indirectly, every woman in the world is facing violence in one form or another by the male gender. It is necessary to discover the evidences of violence against women, causing traumatic stress as more socially knowledgeable concern. The social system approach indicated how the human behavior is triggered by experiences of trauma (Fullerton et al., 2001). The learning about traumatic stress integrated it as a more socially identified issue. Generally, it is viewed that trauma does not happen in normal social settings. It is necessary to escalate the importance of communicating and collective dynamics related to pre and post-traumatic stress disorder on women. The social system approach contributes a context about the traumatic effects, help to identify the PTSD symptoms and its influence on social settings for the abrogation of trauma from women in the society.

Psychobiological phenomenon for the transmission of adaptive characteristics revealed that if the mother is the victim of stress during child bearing stages, the child is likely to have mother's influence of stress whether the mother is present or not. According to the attachment theory, when the child becomes mature and performs the role of a mother, they would have the same influence on their children (Schore, 2001).

In Pakistan, the gender roles are influenced by the traditional values of the society which positions the women lower than men. Patriarchy is one of the early concepts of customary culture. Patriarchal morals embedded in local social order and culture set the gender roles. The Islamic religion gives equal importance to both genders, though the patriarchy is commonly practiced in Pakistani society leading to such type of violence against women. Resultantly, the pre and posttraumatic stress disorder continues to persist.

The research study sets the following goals:

\section{OBJECTIVES}

- To explore the social, economic, and psychological factors of traumatic effects on women.

- To investigate the physical response of social setting to PTSD.

- To suggest a policy for resistance against trauma experience and its control among women.

\section{REVIEW OF LITERATURE}

PTSD is a disorder which is primarily related to females which covers unhealthy mental conditions, being victimized at home in adolescence suffering with extreme violence. The initial conditions and 
adjustable circumstances are later overcome by social support of women. Udwin et al., (2000) comes up with the information that these circumstances are due to facing of tragic traumatic situation at initial stages. Most of these are subjective to life risks, followed by 5 months of anxiety and depression after trauma. It should urgently be treated before reaching to an adverse stage. PTSD would not be identified immediately after one is victimized by it but the information will be aggregated from the childhood experiences and tragedies of the patient at physical, mental, and emotional levels. Moreover, the reports of 5 months' post-depression would also be collected, before the disaster happened. Udwin et al., (2000) suggested that the attainment of results for PTSD is collected after efforts, thinking and implications, still these efforts cause problems in its complete acquirement.

Frans et al., (2005) revealed that the traumas are most frequently linked to PTSD and its further links related to demography are still not understood. It has been proven that the sexual harassment or sex crimes elevated the conditions more than in simple cases, which maybe first-rate PTSD development. PTSD has a wide diversity pertinent to gender, like in males it is ordinarily related to PTSD, but in females it is due to adverse experience of being raped or statutory rape, where its effects are worse.

Thus, from gender to gender, its effects depend on circumstances which an individual had to face especially in past, according to their vulnerabilities. It is found out that women are more vulnerable to PTSD. Influence of different traumas on both genders in PTSD is found by multivariate analysis and various factors contributing in it, in order to disclose further freelance contributing factors.

Simmons, (2007) studied that even though additional analysis is required, still, it remains the burning question that why women have additional development of this disorder as compared to the man. It is essential for females' therapists; certainly, for three reasons. First is that the females have the risk of being a greater subject to trauma as compared to males.

By having a better understanding of what the woman is going through, the therapist will heal her according to the distressing situation. Simmons, (2007) further described that this may be due to the genetic makeup and biological factors of females, different from the males, that develop PTSD. However, no significant empirical and permanent studies or researches have been conducted regarding PTSD, so it is considered that pre-existing vulnerability prevalent in females is associated with genetics and biological elements. Though, a little study has been conducted in this consideration.

Trauma exposure is the causative situation for anxiety disorder to build, genetic and psychosocial threat elements square measure are progressively seen as prognosticators of indicator, marking the beginning of seriousness (Yehuda et al., 2015).

Findings showed the impact of woman's gender role as it shares to variability in man's conformism to masculinity and risk of aggressive reactions. Past research concerning gender conformity and physical violence has largely concentrated on men as both, criminals and victims. Additionally, extended literature highlights the role of individual variances in theorizing and assigning importance to aggressive interactions (Stenius \& Veysey, 2005).

The study of Gill et al., (2008) revealed that when the decline in cognitive and physical situations joins the traumatic disorders, it results in Posttraumatic Stress Disorder (PTSD). Levels of posttraumatic stress disorder elevated in people with minimal wages, which the UN agency present in metropolitan regions related to the overall inhabitants. Through analysis, 250 metropolitan wellbeing maintenance-taking ladies were interrogated for a description of posttraumatic stress disorder about the knowledge of stressful situation.

Engelhard et al., (2001) analyzed that this potential is about the frequency of PTSD in reaction to prenatal period. Roughly 1,371 ladies were enlisted within the initial phases of gestation and 114 of them suffered an underlying gestation failure. After one to four months' gestation damage, they were measured for posttraumatic stress disorder with the Posttraumatic Symptom Scale. Recession was additionally evaluated, the bulk had associate degree initial loss, i.e., among twenty weeks. At first month, the frequency of posttraumatic stress disorder was twenty-five and the severity of symptom was almost like different devastated inhabitants. The ladies with posttraumatic stress disorder had multiplied threat of depression; thirty-four posttraumatic stress disorder incidents. In most cases, the illness is abrupt and continued for quite a few months. 


\section{SIGNIFICANCE OF STUDY}

Considering current situation, an increased number of women affected by post-traumatic stress disorder are analyzed in the subsequent period of time. Post-traumatic stress disorder is a great community issue, that requires the quest for new concepts and hypothetical paradigms to extend the knowledge of the situation and to advance modern and enhanced methods of dealing involvement. There are major aims in this study to improve the current information that why women percentage is higher in post-traumatic stress disorder and to discover the general response of women towards trauma disorder. District Sargodha from Punjab Pakistan was selected as research area. In Pakistan, out of total population, the women percentage is $48.5 \%$ out of which women ages from 25 to 29 is $8.6 \%$ of the population. According to national poverty lines 2015, the percentage of poverty is $24.3 \%$ among the total population. Pakistan attained 153rd place in the global survival index. Having sever effect of illness can compromise one's potential specially for women. Almost 50\% of woman were stated as "distressed women" and out of this, 28\% have anxiety and depression, and $7 \%$ have personality disorders, while $17 \%$ suffer from different psychological disorders in the life course. It is needed to train the women for situation management in distress situation so that the physical and mental ailments could be deceased. It will increase the satisfaction level of life, and the standard of living may improve. Stress coping strategies should be introduced to the women to handle any traumatic situation.

\section{Conceptual framework of handling Traumatic Disorder among women Victims}

The chief aim of this research is to define the factors, issues, and condition of traumatic stress on women. To find insights of these issues, a conceptual framework was designed to access the trauma and its effects on physical and mental health of women.

\section{Women (independent} variable)

\section{Psychological state}

\section{METHODOLOGY}


This study was based on quantitative analysis. Multi stage random sampling technique was used to collect the data, there are 9 psychiatric hospitals in public and private setups in the district Sargodha Punjab Pakistan. Four were selected for the research study upon the expediency of the research responses. A sample of 304 women patients were selected by the proportionate sampling who were experiencing different types of stressful situations. A well-structured questionnaire was developed to ensure the maximum response from the women victims. Nominal scale was used to organize the questionnaire. Statistical Package for the Social Sciences (SPSS) was used to analyze the data.
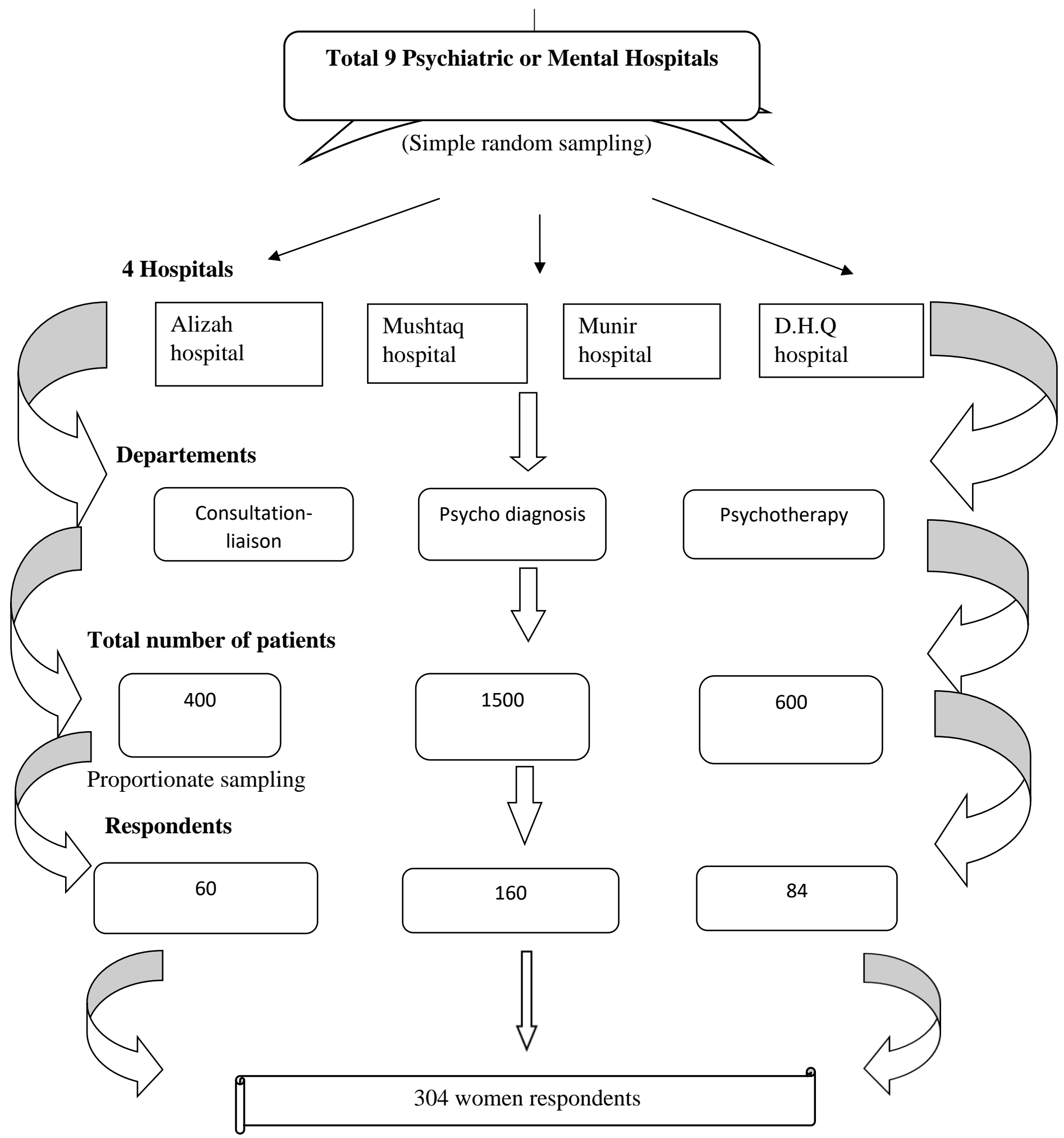


\section{Universe/Population of the study}

Universe of this research is district Sargodha. There are total nine hospitals in district among which four hospitals were selected (Alizah hospital, Mushtaq hospital, Munir hospital and D.H.Q hospital) through simple random sampling and from these hospitals, women were selected who were suffering from trauma.

\section{Sample size}

For this study, sample size of 304 respondents (patients) was chosen. These respondents (patients) were chosen by multistage sampling method; hospitals were selected through simple random sampling, and women of PTSD were selected by proportionate sampling.

\section{Sampling technique}

Sampling mean to valuable implications that would ascend the study results (Creswell \& Miller, 2000). This study is conducted as quantitative method. For the quantitative method, a total of 304 women suffering from PTSD were selected for the research as target sample by using multistage technique. At the first stage, psychiatric hospitals of district Sargodha were selected by simple random sampling. At second stage, four hospitals were selected as target population. At third stage, from each hospital, women were selected suffering from post-traumatic stress condition by proportionate sampling. All the sampled patients were given statement to hide their identities.

\section{Table\#1 Disclosing the demographic features of the respondents when $N=304$}

\begin{tabular}{|c|c|c|c|}
\hline $\mathbf{S} / \mathbf{R}$ & Factors & Variables & Frequency \\
\hline & & $18-28$ & 51.5 \\
\hline \multirow[t]{4}{*}{1.} & Age & $29-38$ & 20.4 \\
\hline & & $39-48$ & 17.6 \\
\hline & & $49-58$ & 5.7 \\
\hline & & above 59 & 4.8 \\
\hline \multirow[t]{3}{*}{2.} & Marital status & Single & 57.3 \\
\hline & & Married & 40.5 \\
\hline & & Widow/Divorce & 2.3 \\
\hline \multirow[t]{2}{*}{3.} & Residential Area & Urban & 72.8 \\
\hline & & Rural & 27.3 \\
\hline \multirow[t]{5}{*}{4.} & Family income & less than 10,000 & 10.5 \\
\hline & & $11,000-24,000$ & 34.3 \\
\hline & & $25,000-40,000$ & 19.0 \\
\hline & & $41,000-54,000$ & 18.8 \\
\hline & & 55,000 or above 55,000 & 17.5 \\
\hline \multirow[t]{3}{*}{5.} & Family structure & Nuclear & 38.8 \\
\hline & & Joint & 56.3 \\
\hline & & Extended & 5 \\
\hline
\end{tabular}

Above table 4.1 gives description of patient's background. This study analyzed responses of $\mathrm{N}=304$ participants. The respondents were only female, the most prevalent age group was 18-28 (51.5\%) and the least frequent was above $59(4.8 \%)$. Majority of them have low family income up to $11,000-$ 24,000 . 
The research observed that those who suffer traumatic situation might have short-term problem in adapting concentration on different life activities but within time and self-care, they usually recover from trauma disorders. On the opposite side, if the signs continue to upshot, and even stays for months or perhaps years, and may affect in everyday life tasks, it will have worse type of PTSD.

Table\#3 This table shows the responses of the respondents about the social exposure of women:

\begin{tabular}{lll}
\hline Social exposure & Yes & No \\
\hline $\begin{array}{l}\text { Talking about the } \\
\text { trauma with other } \\
\text { people. }\end{array}$ & 258 & \\
$\begin{array}{l}\text { Having issues in } \\
\text { performance, trying to } \\
\text { avoid activities, } \\
\text { situations, or places that } \\
\text { take you back to the } \\
\text { trauma. }\end{array}$ & 50 \\
& & \\
$\begin{array}{l}\text { Taking social support } \\
\text { from others. }\end{array}$ & 184 & \\
$\begin{array}{l}\text { Behaving more irritable } \\
\text { or aggressive with } \\
\text { others. }\end{array}$ & 201 & 125 \\
$\begin{array}{l}\text { Feeling isolated or cut } \\
\text { off from others. }\end{array}$ & 142 & 108 \\
\end{tabular}

This table showed that responses of effected women who put off their emotions and activities to shield themselves. Women with anxiety disorder have problem in processing of emotions. Different consultants are trained to assist them to respond and handle the emotions. They'll then assist themselves to train the behavior for healthy method and plan development.

Consequently, it's analyzed that taking social support facilities in handling traumatic situation. Most frequently social support is marked as social relations that give people with real help and involve them into different social associations. The social associations work by giving the impression to be idealistic, kind, and quick out there to help. The same has been analyzed that if the person experienced the neglect of social support, he will have lot of stress and isolation. Different studies disclosed impacts of social support on the treatment of stressful situations (Stenius \& Veysey, 2005).

The outcomes suggested that different categories of traumatic experiences elicit high amounts of negative feelings, during and after the stressed condition among women. These women got distant and psychologically cut off from others and with the situation.

\section{FINDINGS AND CONCLUSION}

In this study, it is discovered that all the various aspects associated with the PTSD have its influence on women; however, this has been very troublesome and disturbing situation based on several circumstances. It's well observed that growth of any trauma will increase the danger of experiencing multiple disturbing situations, multiple traumas appear to be associated with increased PTSD and difficulties in experiencing severe and chronic PTSD. In present study, the two factors, general distress and social support have a great importance because when person go through the trauma, they face the distress which disturb their general day to day dealings. 
Women are one of the important components of society and they have their own roles to perform. When women go through the trauma, they face issues that affect their general life. They could not perform their role in an effective way due to lack of physical and cognitive balance. They face issues like having bad dreams, nightmares, bad memories about trauma, which stop them from staying positive all along the day. Nightmares or bad dreams are related to the general distress of PTSD that needs targeted assessment and treatment. In my findings, the nightmare and dreams are associated with the trauma that someone has experienced in traumatic situation.

All these situations that a women face after experiencing trauma will in return may have difficulty in staying positive and focusing on activities and household work. In present findings, women who face traumatic situation might have short-term problem of adapting concentrating issues on different activities, with time and self-care, they usually recover. On the opposite side, if the signs continue to upshot, and even stays for months or perhaps years, and affect everyday life tasks, this will be a worse condition of PTSD. The self-care may help out the women to cope up the traumatic situation by adapting different techniques to recover quickly.

In this research analysis, it's comprehended that having physical reaction reminded of trauma because a person's body suddenly kicks into high alert due to effect of their trauma. Even if real danger might not occur, their body acts as if it's gone through stress when a traumatic situation happens. This brings outbursts and panic attacks in women. When trauma strikes, there's a necessity to search out for someone for support. Findings supports that trauma exposure may develop the flexibility to handle the situation when it happened again.

After going through trauma women often take social support from their family. Because this help them to handle situation well. But there are some cases in which women refuses to take social support in fear of how her family will react after knowing about the incidence which increases the isolation behavior and make the situation worse for many cases. In findings, it's analyzed that taking social support facilitate in handling traumatic situation. Most frequent social support is marked as social relations that give people real help and involve them into different social associations. The result for the neglect of received social support is in the form of a lot of stress and isolation. Different studies disclosed impacts of social support on the treatment of stressful situations.

So, it is concluded in research study that taking social support is important as women could share their experience instead of suffering alone and not finding any solution to this type of situations. This may also prevent the isolation behavior and let the patient recover fast from their trauma and get socialize with others through outburst of negative emotions.

At the time of the trauma, overall negative feeling was reported despite of traumatic situation. Important thing is finding the overall posttraumatic emotional responding which once reminded of traumatic situation. It is analyzed that person might feel upset after they are reminded of traumatic event. Emotional control may be a complex method that requires initiating, inhibiting, or modulating situation or behavior. The flexibility to control emotional responses to any situation is vital for mental and physical health. Various patients with PTSD regularly experience the suffering within diversity of hallucination, recollections, nightmares, or horrifying feelings, particularly once they are subjected to condition or items corresponding to the distress.

In short, women are greater pillar of the structure of any society. Without a physically or mentally healthy women, we could not imagine a healthy society. Now a day's, women are main contribution in country's economy. They work for their families and play vital role in economic progress as well. So, there is a great need to start taking steps for the women mental health education, training and policy making related to women empowerment. Without that, we will not be able to make our society better. A mentally healthy woman could not only raise her children but leads the nation in a noble way. Thus, men alone could not make a society as we need role of women to shape our families, communities and nation.

\section{RECOMMENDATIONS}

It is recommended to organize the training sessions with the patients of PTSD and let them understand about the deep-down effects and coping strategies related to stress. Person who are facing effects of traumatic situation must facilitate themselves from mental health care institutions for medical and rehabilitation consultation. Different methods of self-care can alter the negative things regarding world. It is highly recommended that people, who are effected by PTSD, should be busy in purposeful 
activities. It is recommended to develop social and moral support mechanism for patients who finds it difficult to keep positive vibes by his/her caregivers, family members and professionals. Government should increase funding for research on Post Trauma Stress Disorder (PTSD) on Women case studies.

\section{REFERENCES}

Cloitre, M., Hyland, P., Bisson, J.I., Brewin, C.R., Roberts, N.P., Karatzias, T., \& Shevlin, M. (2019). Posttraumatic Stress Disorder and Complex Posttraumatic Stress Disorder in the United States: A Population-Based Study. Journal of Traumatic Stress, 32(6), 833-842.

Engelhard, I.M., van den Hout, M.A., \& Arntz, A. (2001). Posttraumatic stress disorder after pregnancy loss. General Hospital Psychiatry, 23(2), 62-6.

Frans, O., Rimmo, P.A., Aberg, L., \& Fredrikson, M. (2005). Trauma exposure and post-traumatic stress disorder in the general population. Acta Psychiatrica Scandinavica, 111(4), 291-9.

Fullerton, C.S., Ursano, R.J., Epstein, R.S., Crowley, B., Vance, K., Kao, T., Dougall, A., \& Baum, A. (2001). Gender Differences in Posttraumatic Stress Disorder After Motor Vehicle Accidents. Am J Psychiatry, 158(9), 1486-91,

Gill, J.M., Page, G.G., Sharps, P., \& Campbell, J.C. (2008). Experiences of Traumatic Events and Associations with PTSD and Depression Development in Urban Health Care-seeking Women. Journal of Urban Health, 85(5), 693-706.

Norris, G.J., \& Olff, M. (2009). The Lifetime Prevalence of Traumatic Events and Posttraumatic Stress Disorder in the Netherlands. Journal of Traumatic Stress, 22(4), 259-67

Schore, A.N. (2001). The Effect of Early Trauma on Right brain Development, affect Regulation, and Infant mental Health. Infant mental health journal, 22(1-2), 201-269.

Simmons, C.A. (2007). Speculation as to why Women "Get" PTSD More Often Than Men. Women \& Therapy.

Stenius, V.M.K., \& Veysey, B.M. (2005). "It's the Little Things" Women, Trauma, and Strategies for Healing. Journal of interpersonal violence, 20(10), 1155-1174.

Udwin, O., Boyle, S., Yule, W., Bolton, D., \& O'Ryan, D. (2000). Risk Factors for Long-term Psychological Effects of a Disaster Experienced in Adolescence: Predictors of Post-Traumatic Stress Disorder. Journal of Child Psychology and Psychiatry, 41(8), 969-79.

Yehuda, R., Hoge, C.W., McFarlane, A.C., Vermetten, E., Lanius, R.A., Nievergelt, C.M., Hobfoll, S.E., Koenen, K.C., Neylan, T.C., \& Hyman, S. E. (2015). Post-traumatic stress disorder, 1, 15057 